\title{
NT-proBNP independently predicts long term mortality after acute exacerbation of COPD - a prospective cohort study
}

Arne Didrik Høiseth ${ }^{1,3^{*}}$, Torbjørn Omland ${ }^{1}$, Tor-Arne Hagve², Pål H Brekke ${ }^{1}$ and Vidar Søyseth ${ }^{1}$

\begin{abstract}
Background: Cardiovascular disease is prevalent and frequently unrecognized in patients with chronic obstructive pulmonary disease (COPD). NT-proBNP is an established risk factor in patients with heart failure. NT-proBNP may also be released from the right ventricle. Thus serum NT-proBNP may be elevated during acute exacerbations of COPD (AECOPD). The prognostic value of NT-proBNP in patients hospitalized with AECOPD is sparsely studied. Our objective was to test the hypothesis that NT-proBNP independently predicts long term mortality following AECOPD.
\end{abstract}

Methods: A prospective cohort study of 99 patients with 217 admissions with AECOPD. Clinical, electrocardiographic, radiological and biochemical data were collected at index and repeat admissions and analyzed in an extended survival analysis with time-dependent covariables.

Results: Median follow-up time was 1.9 years, and 57 patients died during follow-up. NT-proBNP tertile limits were 264.4 and $909 \mathrm{pg} / \mathrm{mL}$, and NT-proBNP in tertiles 1 through 3 was associated with mortality rates of 8.6, 35 and 62 per 100 patient-years, respectively (age-adjusted log-rank $p<0.0001$ ). After adjustment for age, gender, peripheral edema, cephalization and CTnT in a multivariable survival model, the corresponding hazard ratios for dying were 2.4 (0.95-6.0) and 3.2 (1.3-8.1) (with 95\% confidence intervals in parentheses, p-value for trend 0.013).

Conclusions: NT-proBNP is a strong and independent determinant of mortality after AECOPD.

Keywords: Chronic obstructive pulmonary disease, Heart failure, NT-proBNP, Mortality

\section{Background}

Comorbidities are important determinants of outcome and quality of life of patients with chronic obstructive pulmonary disease (COPD) [1]. The extrapulmonary manifestations of COPD include cardiovascular diseases such as cerebral stroke, myocardial infarction (MI), heart failure, and cardiac arrhythmias. These conditions are more common among COPD patients than in the general population, also after adjusting for smoking and other important confounders [2-6]. Moreover, heart disease often remains undiagnosed in these patients [7-10]. This may in part be because the symptoms and signs of $\mathrm{MI}$ and heart failure may mimic an acute exacerbation

\footnotetext{
* Correspondence: a.d.hoiseth@medisin.uio.no

'Division of Medicine, Akershus University Hospital and Institute of Clinical Medicine, University of Oslo, Oslo, Norway

${ }^{3}$ Akershus University Hospital, 1478, Lørenskog, Norway

Full list of author information is available at the end of the article
}

of COPD (AECOPD), but also because the classic symptom and sign of MI, i.e. chest pain and ECG changes, are poorly associated with myocardial injury during AECOPD [11-13]. Using a highly sensitive assay, we have previously shown that nearly three quarters of patients admitted with AECOPD have cardiac troponin $\mathrm{T}(\mathrm{c} \operatorname{TnT})$ above the $99^{\text {th }}$ percentile $(14 \mathrm{ng} / \mathrm{L})$, and that even modest elevation is associated with increased mortality $[14,15]$.

The cardiac peptides B-type natriuretic peptide (BNP) and the $\mathrm{N}$-terminal fragment of its prohormone proBNP, i.e. NT-proBNP, are both established biomarkers of heart failure, [16] and are primarily used for diagnosis, risk stratification and management of heart failure. The natriuretic peptides (NP) have, however, also been shown to be elevated in patients with COPD without known heart failure $[9,15,17]$. It has been proposed that 
the NP may originate from both left and right heart in this setting $[17,18]$. Cor pulmonale, secondary pulmonary hypertension, or hypoxemia may represent important stimuli for the release of NP from the right heart. In stable COPD patients, increased concentration of a NP seems to be associated with poorer long-term survival, [19-22] although this finding not always is reproduced [23]. In one study of 140 stable COPD patients recruited at an outpatient clinic, NT-proBNP levels were associated with mortality in unadjusted analysis, but not after adjustment for echocardiographic variables, suggesting that underlying heart disease may be the cause of both increased NT-proBNP and mortality [21].

During AECOPD the NP levels are higher than in the stable state, $[18,23,24]$ and the stimuli for their release may be more complex. Three papers addressing NP as prognostic markers after AECOPD do not conclude uniformly, $[15,17,18]$ as only Medina found significant association with long-term mortality. Consequently, it remains unresolved whether circulating natriuretic peptides measured during AECOPD provide independent long-term prognostic information. Moreover, the potential incremental prognostic value of combining cardiac troponins, using contemporary high sensitivity assays, and NP still remains unresolved. The release of the two biomarkers may in part be due to the same mechanisms, but their levels during exacerbations have shown conflicting degrees of correlation $[15,25]$. In a single study only have both NT-proBNP and cTnT during AECOPD been measured and related to survival [15]. cTnT, measured by a former generation assay, and NT-proBNP above the upper limits of normal were both associated with increased 30 days mortality, but not with 12 month mortality. Further, while NT-proBNP elevation provided incremental prognostic information to cTnT, the converse was not true.

We hypothesized that the concentrations of NTproBNP and cTnT on admission for exacerbation of AECOPD, as measured by a highly sensitive assay (hscTnT), provide independent prognostic information about long-term mortality.

\section{Methods \\ Material}

During 23 months in 2005 and 2006, all patients admitted with AECOPD were eligible for inclusion in this prospective cohort study. If patients had more than one admission during the inclusion period, data from all admissions were recorded and used in the analyses, as described in the statistics section. On each admission we recorded clinical data, ECGs, chest radiographs, and results from blood analyses. The clinical data recorded were heart rate, blood pressure, body temperature, respiratory rate, arterial blood gases $\left(\mathrm{pH}, \mathrm{PaCO}_{2}, \mathrm{PaO}_{2}\right)$, arterial oxygen saturation $\left(\mathrm{SaO}_{2}\right)$, wheezing, chest pain, and the use of accessory muscles of respiration. ECGs were analyzed for the presence of P pulmonale, QRS axis deviation, signs of acute ischemia (ST-segment depression or elevation), and previous MI (T-wave inversion, pathological Q-wave, loss of R, or left bundle branch block, and by using the cardiac infarction injury score (CIIS), where a score $\geq 20$ indicates high probability of prior MI) [26]. Two independent investigators, who were blinded to all clinical data, conducted the ECG analyses. Differences were settled by consensus regarding the qualitative analyses, and by a third investigator regarding CIIS (when the two initial scorings were on opposite sides of 20). Two blinded investigators examined the radiographs for the presence of cephalization of the lung veins, infiltrates, cardiomegaly, or pleural effusions.

Haemoglobin, leucocyte, neutrophil and platelet counts, electrolytes, blood glucose, and serum CRP were recorded from the hospital records. Serum and plasma from blood drawn on admission were stored at $-80^{\circ} \mathrm{C}$ for subsequent analysis of creatinine, hs-cTnT and NTproBNP (Roche Diagnostics, Mannheim, Germany). The NT-proNBP assay has a lower limit of detection of $5.0 \mathrm{pg} / \mathrm{mL}$. The coefficients of variation are reported to be $4.2 \%, 2.4 \%$ and $1.3 \%$ at concentrations of $44 \mathrm{pg} / \mathrm{mL}$, $126 \mathrm{pg} / \mathrm{mL}$ and $2410 \mathrm{pg} / \mathrm{mL}$, respectively. Body mass index (BMI) and spirometry during stable phase were recorded when available. Medical history was obtained by patient interview and by retrieving information from hospital records. Patients were categorized as current, former or never smokers. We also recorded the number of admissions with AECOPD during the 12 months prior to inclusion. The endpoint was length of survival after the initial admission, with end of follow-up on December $31^{\text {st }}$ 2008. Survival status and dates of death were retrieved from the National Population Registry.

All included patients gave written informed consent. The study protocol was approved by the Data Inspectorate and by the Regional Committee for Research Ethics. Additional information regarding the inclusion procedure and the study population is available in the additional material [see Additional file 1] and an earlier paper [14].

\section{Statistical analyses}

First, NT-proBNP was categorized by tertiles, and the mortality rates between the NT-proBNP tertiles were compared using age-adjusted log-rank test. Investigation of potential confounding was done in two steps: First by identifying variables associated with NT-proBNP, and then by analyzing which of these that were also associated with mortality. Univariable baseline associations between NT-proBNP tertiles and covariables were analyzed using Chi-square or Fisher's exact test for 
categorical variables and Kruskall-Wallis test for continuous variables. Then, for the covariables that were associated with NT-proBNP with a p-value $<0.20$, we investigated the association between the corresponding covariable and mortality using an age-adjusted log-rank test. In this analysis, continuous variables were categorized: Number of admissions during the past year was categorized as 0,1 or $\geq 2$, as in the ECLIPSE study [27]. hs-cTnT was categorized into three groups according to cut-offs at 14 and $40 \mathrm{ng} / \mathrm{L}$, as these cut-offs have shown to discriminate well with regard to survival [14]. The remaining continuous covariables were dichotomized at pre-specified limits: $\mathrm{FEV}_{1} / \mathrm{FVC}$ at the mean (0.45), BMI at the lower limit of normal $\left(20 \mathrm{~kg} / \mathrm{m}^{2}\right), \mathrm{CRP}$ at $50 \mathrm{mg} / \mathrm{L}$, and creatinine at $100 \mu \mathrm{mol} / \mathrm{L}$.

The variables associated with both NT-proBNP and mortality $(\mathrm{p}<0.20$ in both tests above) were included in a multivariable survival analysis. For these variables, we also investigated potential effect modification and tested for homogeneity using Mantel-Haenszel test [28]. If this indicated effect modification of the association between NT-proBNP and mortality, a productterm between NT-proBNP and the corresponding covariable was included in the initial multivariable survival model. If the product-term proved significant with $\mathrm{p}$-value $<0.05$, the covariable in question was considered an effect modifier.

Up until this point, only the index observations were used, but for the final survival analysis, we used an extended Cox regression analysis with time-dependent covariables, [29] such that covariables that may change between admissions (i.e. all covariables except age at inclusion, gender, lung function, BMI, and medical history) were updated at each subsequent admission. Using a backward elimination procedure, the model was reduced by removing variables with p-values $>0.05$ provided that the coefficient of the association between mortality and NT-proBNP changed less than 20\%. Age and gender were kept in the model by convention. Finally, the interaction terms between NT-proBNP and age, gender, and creatinine were added to the model to check whether important interactions had been overlooked.

We performed four supplementary survival analyses: i) The described analysis restricted to the patients with no history of heart failure, ii) with NT-proBNP as a continuous variable (log-transformed; $\ln B N P)$, iii) with NT-proBNP categorized at 1000 and $2500 \mathrm{pg} / \mathrm{mL}$, as suggested by Abroug et al., [30] and iv) the described analysis restricted to patients without chest pain or ECG changes indicative of acute ischemia (i.e. patients that may fulfill the criteria for an MI).

The proportional hazards assumption was checked by the Martingale residuals on standard Cox regression models using the index observations only. Analyses of effect modification were done using STATA 10 (Stata Corp LP, TX, USA). All other analyses were done using SAS 9.2 (SAS Institute Inc., Cary, NC, USA).

\section{Results}

99 patients were included. Mean age at inclusion was 71.5 years (standard deviation (SD) 9.0 years), and 47 $(47 \%)$ were female. Spirometry measurement from the stable state was available in 88 patients. Mean $\mathrm{FEV}_{1}$ was 0.91 liter (SD 0.45 liter), and mean $\mathrm{FEV}_{1} / \mathrm{FVC}$ was $45.3 \%$ (SD 14.2\%). Median NT-proBNP concentration at inclusion was $423.3 \mathrm{pg} / \mathrm{mL}$, and the tertile limits were 264.4 and $909 \mathrm{pg} / \mathrm{mL} .41$ patients were readmitted during the inclusion period, adding to a total of 219 admissions. In 217 of these, we had NT-proBNP measured, with a median of $560.4 \mathrm{pg} / \mathrm{mL}$. Among the patients with more than one NT-proBNP measurement, the median change (absolute value) from the previous measurement was 66\% (IQR 41-150\%). Three patients had two consecutive NT-proBNP measurements less than $5 \%$ apart, but none of these changed tertiles. The prevalence of categorical variables and the mean of continuous variables in each tertile of NT-proBNP at inclusion are reported in Table 1 for those variables associated with NT-proBNP $(p<0.20)$. Among the variables not associated with NT-proBNP were: a history of coronary artery disease (27\%), arterial hypertension (31\%), smoking status (48\% current smokers), chest pain on admission (10\%), kidney function (mean creatinine $76 \mu \mathrm{g} / \mathrm{L}$ ), P pulmonale (25\%), right axis deviation (10\%), atrial fibrillation (7\%), prior MI (40\%), and ischemia in ECG (27\%). Median NT-proBNP concentrations (with interquartile range) among patients with 0,1 and $\geq 2$ admissions the past 12 months were 339 (183-1054), 679 (154-1438) and $421(157-1389) \mathrm{pg} / \mathrm{mL}$, respectively $(\mathrm{p}=0.826)$. The correlation between NT-proBNP and hs-cTnT was moderate (both logarithmically transformed, Pearson rho $=0.34, \mathrm{p}=0.0006$ ).

During a median follow-up of 1.9 years, 57 (58\%) patients died, with an overall mortality rate of 28.7 per 100 patient-years. NT-proBNP tertiles on inclusion were associated with increasing mortality rates, i.e. 8.6 (95\% confidence interval 4.3-17), 35 (23-54) and 62 (43-91) per 100 patient-years, respectively (Figure 1, age-adjusted log-rank p-value $<0.0001$ ). When applying the cut-offs suggested by Abroug, [30] the mortality rates were 19, 25 and 120 per 100 patient-years among patients with NT-proBNP $<1000, \quad 1000-2500$ and $\geq 2500 \mathrm{pg} / \mathrm{mL}$, respectively (age-adjusted log-rank p-value $<0.0001$ ).

Of the variables that were associated with NT-proBNP concentrations, history of diabetes and lung function failed to show any association with mortality and were therefore not included in further analyses. For the remaining covariables, stratified analyses of mortality 
Table 1 Prevalence or mean of relevant covariables in each tertile of NT-proBNP at baseline

\begin{tabular}{|c|c|c|c|c|}
\hline & \multicolumn{3}{|c|}{ NT-proBNP, pg/mL } & \multirow[t]{2}{*}{ p-value } \\
\hline & $\begin{array}{l}\text { Tertile } 1 \\
(<264.4)\end{array}$ & $\begin{array}{l}\text { Tertile } 2 \\
(264.4-909)\end{array}$ & $\begin{array}{l}\text { Tertile } 3 \\
(\geq 909)\end{array}$ & \\
\hline Female, n (\%) & $16(48)$ & $18(55)$ & $13(39)$ & 0.463 \\
\hline Age (years), mean (SD) & $66.0(7.4)$ & $71.9(8.2)$ & $76.6(8.1)$ & $<0.0001$ \\
\hline BMI $\left(\mathrm{kg} / \mathrm{m}^{2}\right)$, mean (SD) & $23.2(5.3)$ & $23.6(6.1)$ & $21.3(3.9)$ & 0.149 \\
\hline \multicolumn{5}{|l|}{ Medical history } \\
\hline $\mathrm{FEV}_{1} / \mathrm{FVC}$, mean $(\mathrm{SD})^{*}$ & $0.46(0.16)$ & $0.45(0.14)$ & $0.46(0.13)$ & 0.943 \\
\hline $\mathrm{FEV}_{1}(\mathrm{~L})$, mean $(\mathrm{SD})^{*}$ & $0.99(0.55)$ & $0.81(0.36)$ & $0.94(0.39)$ & 0.305 \\
\hline $\mathrm{FEV}_{1}\left(\%\right.$ of pred.), mean $(\mathrm{SD})^{*}$ & $33(18)$ & $31(20)$ & $36(20)$ & 0.375 \\
\hline Heart failure, $n(\%)$ & $3(9.1)$ & $4(12)$ & $7(21)$ & 0.445 \\
\hline Diabetes Mellitus, n (\%) & $3(9.1)$ & $5(15)$ & 0 & 0.008 \\
\hline Atrial fibrillation, n (\%) & $1(3.0)$ & $3(9.1)$ & $6(18)$ & 0.149 \\
\hline Admissions past 12 months & & & & 0.814 \\
\hline$\overline{0}$ & $13(35)$ & $14(38)$ & $10(27)$ & \\
\hline 1 & $8(31)$ & $7(27)$ & $11(42)$ & \\
\hline$\geq 2$ & $12(33)$ & $12(33)$ & $12(33)$ & \\
\hline \multicolumn{5}{|l|}{ Findings on admission } \\
\hline Peripheral edema, n (\%) & $3(9.1)$ & $6(18)$ & $9(27)$ & 0.179 \\
\hline Cephalization, n (\%) & $2(6.1)$ & $3(9.1)$ & $11(33)$ & 0.007 \\
\hline $\mathrm{SaO}_{2}(\%)$, mean (SD) & $92.1(3.0)$ & $89.0(6.8)$ & $88.1(9.0)$ & 0.177 \\
\hline \multicolumn{5}{|l|}{ Biochemistry } \\
\hline CRP (mg/L), median (IQR) & $20(2.0-35)$ & $38(17-71)$ & $54(2.0-84)$ & 0.071 \\
\hline hs-cTnT (ng/L), median (IQR) & $14(8.3-26)$ & $31(15-41)$ & $44(22-58)$ & 0.0006 \\
\hline Creatinine $(\mu \mathrm{mol} / \mathrm{L})$, median (IQR) & $64(55-79)$ & $65(53-89)$ & $75(60-91)$ & 0.213 \\
\hline
\end{tabular}

The table includes variables associated with NT-proBNP tertiles $(\mathrm{p}<0.20)$ with past admissions, lung and kidney function added to better characterize the cohort. * Spirometry available in 88 patients ( $\mathrm{n}=28,28$ and 29 in tertiles 1-3). SD, standard deviation; IQR, interquartile range; BMI, body mass index; CRP, C-reactive protein; hs-cTnT, high-sensitivity cardiac troponin T.

$\mathrm{N}=99$ unless otherwise specified.

through the tertiles of NT-proBNP were then performed (Table 2). Mantel-Haenszel tests showed no statistically significant effect modification of the association between NT-proBNP and mortality by any of the covariables

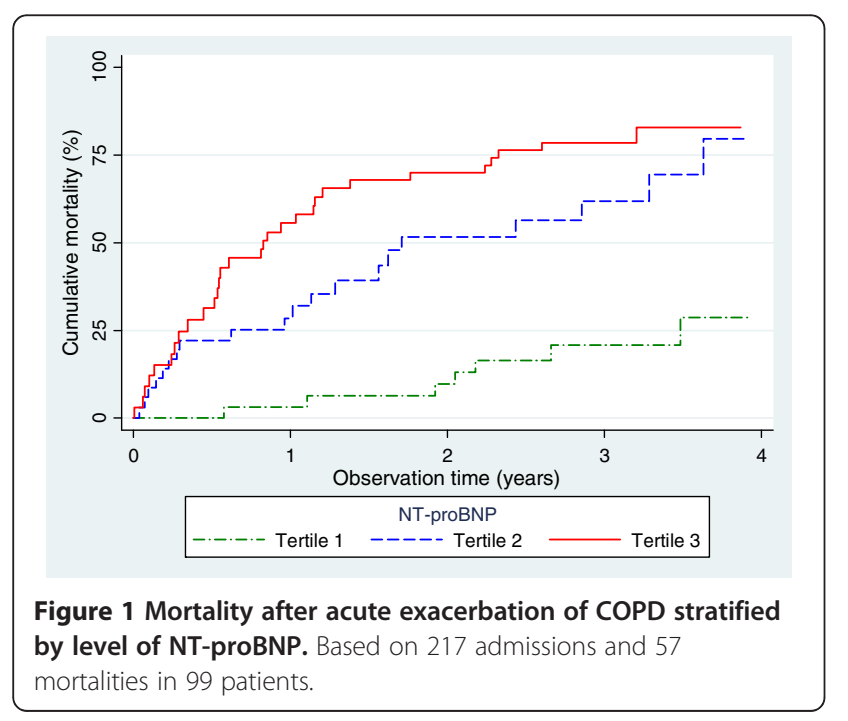

listed in Table 2, and the following variables were included in the initial multivariable model: age, gender, BMI, history of heart failure, atrial fibrillation on admission, peripheral edema, cephalization of the lung veins, CRP, and hs-cTnT. Reduction of the model gave the final model in Table 3, showing increasing mortality with increasing levels of NT-proBNP ( $p=0.013$ for trend). hscTnT, gender, peripheral edema, and cephalization of the lung veins were also independently associated with mortality. None of the interaction terms investigated proved statistically significant ( $\mathrm{p}$-values $>0.05$ ). Using the natural logarithm of the NT-proBNP concentration $(\ln B N P)$ as a continuous variable in the final model showed a hazard ratio of 1.5 (95\% CI: 1.2-1.9, p=0.0005) per unit increase in $\operatorname{lnBNP}$. By adhering to the model reduction described, BMI and CRP were eliminated from the model both when analyzed as continuous and dichotomized variables. Similarly, analyzing hs-cTnT continuously and categorized made no noteworthy change in the model. Patients with a history of heart failure had non-significantly higher NT-proBNP concentrations (median 1554 vs. $400 \mathrm{pg} / \mathrm{mL}, \mathrm{p}=0.102$ ), and when 
Table 2 Mortality (m), mortality rate (MR, per 100 patient-years) in NT-proBNP tertiles, and mortality rate ratio per tertile increase in NT-proNBP

\begin{tabular}{|c|c|c|c|c|c|}
\hline & \multicolumn{3}{|c|}{ NT-proBNP (pg/mL) } & \multicolumn{2}{|c|}{ Mortality Rate Ratio } \\
\hline & $\begin{array}{l}\text { Tertile } 1 \\
(<264.4)\end{array}$ & $\begin{array}{l}\text { Tertile } 2 \\
(264.4-909)\end{array}$ & $\begin{array}{l}\text { Tertile } 3 \\
(\geq 909)\end{array}$ & Unadjusted & Adjusted* \\
\hline & m (MR) & m (MR) & m (MR) & & \\
\hline Gender & & & & & $2.4(1.8-3.3)$ \\
\hline Female & $6(16.5)$ & $12(35)$ & $12(67)$ & $2.1(1.3-3.3)$ & \\
\hline Male & $1(1.9)$ & $8(39)$ & $18(51)$ & $2.8(1.8-4.2)$ & \\
\hline Age, years & & & & & $2.3(1.6-3.2)$ \\
\hline$<65$ & $1(5.4)$ & $1(70)$ & $1(15)$ & $1.8(0.49-6.8)$ & \\
\hline $65-74$ & $5(7.9)$ & $11(33)$ & $10(65)$ & $3.3(1.9-5.6)$ & \\
\hline$\geq 75$ & $1(11)$ & $8(39)$ & $19(60)$ & $1.7(1.0-2.8)$ & \\
\hline $\mathrm{BMI}, \mathrm{kg} / \mathrm{m}^{2}$ & & & & & $2.3(1.7-3.2)$ \\
\hline$<20$ & $2(9.6)$ & $8(45)$ & $11(64)$ & $2.1(1.2-3.5)$ & \\
\hline$\geq 20$ & $5(7.2)$ & $9(30)$ & $18(50)$ & $2.5(1.6-3.7)$ & \\
\hline History of DM & & & & & $2.4(1.7-3.2)$ \\
\hline No & $6(7.6)$ & $16(33)$ & $29(57)$ & $2.4(1.7-3.3)$ & \\
\hline Yes & $1(8.8)$ & $4(21)$ & $1(44)$ & $2.6(0.8-8.4)$ & \\
\hline Cephalization & & & & & $2.0(1.4-2.7)$ \\
\hline No & $7(8.0)$ & $19(37)$ & $13(31)$ & $1.9(1.3-2.8)$ & \\
\hline Yes & 0 & $1(30)$ & $17(150)$ & $2.2(1.2-4.2)$ & \\
\hline Atrial fibrillation & & & & & $2.3(1.7-3.1)$ \\
\hline No & $7(8.0)$ & $19(36)$ & $24(50)$ & $2.3(1.6-3.2)$ & \\
\hline Yes & 0 & $1(41)$ & $6(109)$ & $2.3(0.95-5.6)$ & \\
\hline Peripheral edema & & & & & $2.3(1.7-3.1)$ \\
\hline No & $5(6.4)$ & $15(32)$ & $17(38)$ & $2.2(1.5-3.2)$ & \\
\hline Yes & $2(17)$ & $5(68)$ & $13(146)$ & $2.4(1.5-4.1)$ & \\
\hline $\mathrm{SaO}_{2}<90 \%$ & & & & & $2.3(1.7-3.1)$ \\
\hline No & $5(6.8)$ & $12(33)$ & $17(50)$ & $2.5(1.7-3.8)$ & \\
\hline Yes & $2(12)$ & $8(42)$ & $13(68)$ & $1.9(1.2-3.2)$ & \\
\hline CRP, mg/L & & & & & $2.4(1.7-3.2)$ \\
\hline$<50$ & $6(8.2)$ & $13(50)$ & $13(38)$ & $2.0(1.4-3.1)$ & \\
\hline$\geq 50$ & $1(6.0)$ & $7(24)$ & $17(90)$ & $3.0(1.8-5.1)$ & \\
\hline hs-cTnT, ng/L & & & & & $1.8(1.3-2.5)$ \\
\hline$<14$ & $2(4.3)$ & $1(10)$ & 0 & $0.83(0.18-3.9)$ & \\
\hline $14-40$ & $4(12)$ & $10(30)$ & $10(71)$ & $2.5(1.5-4.4)$ & \\
\hline$\geq 40$ & $1(10)$ & $9(78)$ & $20(67)$ & $1.5(0.94-2.3)$ & \\
\hline All, crude MRR & $7(7.8)$ & $20(36)$ & $30(56)$ & $2.4(1.7-3.2)$ & \\
\hline
\end{tabular}

Based on 217 admissions and 57 mortalities among 99 patients. Mortality rate ratio expressed as score test for trend for a one tertile increase in NT-proNBP *Adjusted for the corresponding covariable. BMI, body mass index; DM, diabetes mellitus; CRP, C-reactive protein; hs-cTnT, high-sensitivity cardiac troponin T.

restricting the analysis to the 85 patients without history of heart failure, the associations with mortality remained practically unchanged (Table 3 ). At the index admission, patients with $(n=35)$ and without $(n=64)$ chest pain or ECG signs of acute ischemia had median NT-proBNP concentrations 655 (IQR 197-1311) and 345 (IQR 1451312) $\mathrm{pg} / \mathrm{mL}$, respectively (p-value 0.219). When restricting the analysis to admissions without chest pain or ST-T changes, the association between cTnT and mortality increased markedly while the association between NT-proBNP and mortality was moderately attenuated and was no longer statically significant (Table 3 ).

None of the models violated the proportional hazards assumption.

\section{Discussion}

The new and important findings of the current study are that higher levels of NT-proBNP during AECOPD are 
Table 3 Hazard ratios for dying after admission for acute exacerbation of COPD

\begin{tabular}{|c|c|c|c|c|c|c|c|c|}
\hline \multirow[t]{3}{*}{ Variable } & \multicolumn{4}{|c|}{ All patients* } & \multirow{2}{*}{\multicolumn{2}{|c|}{$\begin{array}{c}\begin{array}{c}\text { Patients with no history of } \\
\text { heart failuret }\end{array} \\
\text { Adjusted }\end{array}$}} & \multirow{2}{*}{\multicolumn{2}{|c|}{$\begin{array}{c}\text { Patients with no chest pain } \\
\text { or ischemiaf } \\
\text { Adjusted }\end{array}$}} \\
\hline & \multicolumn{2}{|c|}{ Univariate } & \multicolumn{2}{|c|}{ Adjusted } & & & & \\
\hline & $\begin{array}{l}\text { Hazard ratio } \\
(95 \% \mathrm{Cl})\end{array}$ & p-value & $\begin{array}{l}\text { Hazard ratio } \\
(95 \% \mathrm{Cl})\end{array}$ & p-value & $\begin{array}{l}\text { Hazard ratio } \\
(95 \% \mathrm{Cl})\end{array}$ & $p$-value & $\begin{array}{l}\text { Hazard ratio } \\
(95 \% \text { Cl) }\end{array}$ & $p$-value \\
\hline Age, per 5 years & $1.3(1.08-1.5)$ & 0.003 & $0.99(0.83-1.2)$ & 0.872 & $0.95(0.78-1.2)$ & 0.643 & $0.98(0.75-1.3)$ & 0.860 \\
\hline Female & $1.4(0.81-2.3)$ & 0.252 & $2.0(1.1-3.6)$ & 0.020 & $1.7(0.87-3.3)$ & 0.119 & $2.8(1.2-6.8)$ & 0.020 \\
\hline Peripheral edema & $3.2(1.9-5.5)$ & $<0.0001$ & $2.1(1.2-3.8)$ & 0.014 & $2.1(1.0-4.2)$ & 0.044 & $2.6(1.1-6.1)$ & 0.032 \\
\hline Cephalization & $4.5(2.5-8.0)$ & $<0.0001$ & $2.2(1.2-4.2)$ & 0.014 & $2.2(1.0-4.8)$ & 0.049 & $3.4(1.2-9.8)$ & 0.022 \\
\hline hs-cTnT, ng/L & & $\begin{array}{l}p \text { for trend } \\
0.0001\end{array}$ & & $\begin{array}{l}p \text { for trend } \\
0.004\end{array}$ & & $\begin{array}{l}p \text { for trend } \\
0.008\end{array}$ & & $\begin{array}{l}p \text { for trend } \\
0.004\end{array}$ \\
\hline$<14$ & 1 & & 1 & & 1 & & 1 & \\
\hline $14-40$ & $6.3(1.9-21)$ & 0.003 & $4.3(1.2-15)$ & 0.024 & $4.5(1.3-16)$ & 0.021 & $9.4(1.2-77)$ & 0.036 \\
\hline$\geq 40$ & $12(3.5-38)$ & $<0.0001$ & $6.5(1.8-24)$ & 0.005 & $6.4(1.7-24)$ & 0.007 & $16(1.7-140)$ & 0.013 \\
\hline NT-proBNP, tertile & & $\begin{array}{l}\text { p for trend } \\
<0.0001\end{array}$ & & $\begin{array}{l}p \text { for trend } \\
0.013\end{array}$ & & $\begin{array}{l}p \text { for trend } \\
0.030\end{array}$ & & $\begin{array}{l}p \text { for trend } \\
0.211\end{array}$ \\
\hline $1(<264.4 \mathrm{pg} / \mathrm{mL})$ & 1 & & 1 & & 1 & & 1 & \\
\hline $2(264.4-909 \mathrm{pg} / \mathrm{mL})$ & $4.3(1.8-10)$ & 0.0009 & $2.4(0.95-6.0)$ & 0.064 & $2.7(1.0-7.4)$ & 0.049 & $2.1(0.60-7.5)$ & 0.247 \\
\hline $3(\geq 909 \mathrm{pg} / \mathrm{mL})$ & $6.9(3.0-16)$ & $<0.0001$ & $3.2(1.3-8.1)$ & 0.012 & $3.3(1.2-9.1)$ & 0.023 & $2.5(0.59-9.0)$ & 0.167 \\
\hline
\end{tabular}

*Based on 217 admissions and 57 mortalities among 99 patients in an extended Cox analysis with time dependent covariables. †Based on 185 admissions among 85 patients (46 mortalities). ¥Based on 137 admissions among 64 patients (30 mortalities). hs-cTnT, high-sensitivity cardiac troponin T.

associated with increased long-term mortality, and that this association is independent of important clinical, radiographic, pulmonary function, and biochemical, variables, including cTnT. Although we observed a moderately strong association between NT-proBNP and cTnT, NT-proBNP provided prognostic information above and beyond cTnT.

The prevailing view is that the primary stimulus for NT-proBNP release is myocardial strain in the face of increased right or left ventricular filling pressures [31,32]. Additionally, it has been shown that hypoxia stimulates the natriuretic peptide system [33]. Of these, both hypoxia and increased pressure in the right heart may be present in COPD, both in stable state and during exacerbations. Although there was a trend against higher concentrations of NT-proBNP with lower $\mathrm{SaO}_{2}$, this association was not statistically significant. In the absence of echocardiograms, we analyzed ECGs for signs of right ventricular hypertrophy/pressure overload, but found no association with NT-proBNP level. Moreover, the association between NT-proBNP and mortality was present also when adjusting for peripheral edema, a clinical feature of elevated right ventricular filling pressures and for decades known as a strong predictor of mortality in COPD. [34] Several studies have shown that left heart failure is relatively common in COPD patients, $[2-4,9,35,36]$ and we find it reasonable to assume that this contributes to the release of NT-proBNP during AECOPD.

Guidelines provide cut-offs to rule heart failure in or out in stable patients. Attempts have been made to make similar decision limits in the acute setting, $[30,37,38]$ but the grey zone is wide, and such recommendations have not been incorporated in the guidelines. Therefore, in the absence of established cut-offs in the acute setting, we chose to explore the data by analyzing NT-proBNP both as a continuous and categorical variable, categorized by tertiles in the main analysis. Categorization by NT-proBNP concentrations of 1000 and $2500 \mathrm{pg} / \mathrm{mL}$, as suggested by Abroug, [30] also discriminated well. However, we found that a lower cut-off also provided prognostic information, with the lower tertile in our material not being far from the limit to rule heart failure very improbable in the PRIDE algorithm (264.4 and $300 \mathrm{pg} / \mathrm{mL}$, respectively) [37]. We found an association between NT-proBNP concentrations and mortality with both categorizations, as well as analyzed as a logarithmically transformed continuous variable. The association between NT-proBNP tertiles and mortality remained practically unchanged when restricting the analysis to patients with no known history of heart failure, and it is not unlikely that unrecognized left heart failure contributes to the mortality in AECOPD. In our study, 24\% of NT-proBNP measurements were above $1800 \mathrm{pg} / \mathrm{mL}$, and $18 \%$ were above $2500 \mathrm{pg} / \mathrm{mL}$, indicating a high probability of concomitant left heart failure in one of four to one of five AECOPD admissions [30,37]. The corresponding proportions were $18 \%$ and $12 \%$ after excluding patients with a history of heart failure.

We found cTnT to be more strongly associated with mortality than NT-proBNP. The pathobiology underlying troponin release is multifaceted. Recently, six potential mechanisms of troponin release have been proposed 
[39], cardiomyocyte necrosis being the most common. Three alternative mechanisms are cellular release of proteolytic troponin degradation products, increased cellular wall permeability with the release of intact cardiac troponin, and active secretion of vesicles containing cardiac troponin. These may occur during AECOPD, with increased wall stress and hypoxemia, factors that also stimulate the production and release of NT-proBNP. If that were the case, we would expect some degree of correlation between hs-cTnT and NT-proBNP. In previous studies, correlations between NT-proBNP and cTnT, and between BNP and cTnI have been found to be $\mathrm{r}=0.46(\mathrm{p}<0.001)$ and $\mathrm{r}=0.006(\mathrm{p}=0.438)$, respectively, during AECOPD [15,25]. Different study design as well as different proteins being measured may explain these diverging results. In the present study, the correlation coefficient between hs-cTnT and NT-proBNP (both logtransformed) was 0.34 , and the association between hscTnT and mortality, as previously published, [14] did not change notably when we took NT-proBNP into account, suggesting a relative pathobiological independence between these biomarkers.

When excluding patients with ischemic ST-T changes or chest pain, the association between NT-proBNP and mortality was moderately attenuated and no longer significant (Table 3, two rightmost columns). This may be partly due to reduced statistical power. However, the point estimate for the strength of the association also was reduced, which suggests that the association between NT-proBNP and mortality was stronger among patients with signs or symptoms of myocardial ischemia. Because of the limited power and the retrospective nature of these analyses, these observations should be interpreted with caution.

Our findings that NT-proBNP and cTnT are independent predictors of mortality, are in accordance with recent observations in both patients with chronic heart failure and stable coronary artery disease, $[40,41]$ as well as in the general population, $[42,43]$ demonstrating that NT-proBNP and cTnT measured with a sensitive assay provide complementary prognostic information. This has not previously been shown in an AECOPD cohort: Medina et al. found 3.9 times increased 1-year mortality in patients with NT-proBNP $>459.9 \mathrm{pg} / \mathrm{mL}$, but did not analyze troponin [17]. Chang et al. investigated $c \operatorname{TnT}$ (using a conventional assay) and NT-proBNP with regard to mortality after AECOPD, and found that either biomarker above the upper limit of normal was associated with increased 30 days mortality, but not with 12 month mortality [15]. The 1-year mortality in Chang's study was $18 \%$ compared to $30 \%$ in the present study. We also report a higher mortality rate than Stolz et al., who observed a $22 \%$ mortality rate after 2 years of follow-up and no significant association between BNP and long-term mortality [18]. That we found higher overall mortality may in part explain why we found significant differences also in long-term survival. Moreover, we have included data from repeat admissions in our analysis. It is possible that we have registered some important events during follow-up that were missed by the previous studies. The reasons for the lower survival in our study than in those of Stolz and Chang are uncertain. The age, gender composition, lung function, comorbidities and status on admission appear to be comparable across the studies, and do not explain the survival differences. Our unselected cohort may be more representative of "real life" patients as we did not exclude patients with AECOPD and radiological infiltrates $(11 \%)$, and this is likely to explain part of the differences in survival. The mortality in our study is within the range that is reported in a 2009 review on COPD exacerbation [44]. In contrast to the report by Chang et al., we found that cTnT, even in modest concentrations, is more strongly associated with mortality than is NT-proBNP.

The survival analysis was done by using an extended Cox regression model with time-dependent covariables. The model is not widely used, but is well described in standard textbooks on survival analysis $[29,45]$. Importantly, compared to a standard Cox regression model, both the number of observations, the number of events and the observation time is unchanged, so the data are not inflated. Time is counted from inclusion until death or censoring while variables that may vary between admissions are updated at each admission. In our opinion, such models generally reflect the true associations between the recorded variables and the outcome more accurately than standard models. And although these repeat recordings are incomplete (120 of 191 readmissions), we have previously demonstrated that this model has better fit than a model with baseline observations only [14].

The term "frequent exacerbation phenotype" has been introduced over the past years, and previous exacerbation is the best predictor of future exacerbations [27]. As we included patients on admission for exacerbation, it is likely that frequent exacerbators are overrepresented in our material compared to a general COPD cohort. We registered the number of exacerbations in the year prior to inclusion to investigate if frequent exacerbations were associated with NT-proBNP, but failed to find such association (Table 1). Thus we do not believe that exacerbation frequency bias the results of our analyses.

Among the weaknesses of this study is the relatively low number of patients. Nevertheless, we have found a strong and statistically significant association with a clinically important endpoint. Thus, the sample size and thereby the power of the study should be appropriate. Moreover, when comparing our baseline data with those 
from other studies in the field, [15,46,47] our cohort appears to be representative. Heart failure and pulmonary embolism were not systematically investigated. This would be of interest as it might contribute to troponin release, NT-proBNP increase, and mortality. Echocardiography would provide valuable data, but was beyond the scope of the present study. We did not investigate cause of death. Only four patients were autopsied, and we believe that the cause of death as recorded on the death certificates differentiates poorly between the relevant diagnoses.

\section{Conclusions}

Increasing levels of NT-proBNP are independently associated with long-term mortality after AECOPD, also after multivariable adjustment including the level of cTnT, cephalization on chest radiograph, peripheral edema and gender. Unrecognized concomitant left heart failure may contribute to the increased mortality.

\section{Additional file}

Additional file 1: is a word document containing additional information on the patient recruitment and data collection.

There are also some detailed results regarding diagnoses made on later admissions and their relation to the outcome.

\section{Competing interests}

Prof. Omland has received speakers' honoraria from Roche Diagnostics, Siemens Healthcare Diagnostics, and Abbott laboratories, manufacturers of assays for B-type natriuretic peptides.

Akershus University Hospital has received research support from Roche Diagnostics and Abbott laboratories, manufacturers of assays for B-type natriuretic peptides.

Doctors Høiseth, Hagve, Brekke and Søyseth have no disclosures.

\section{Authors' contributions}

All authors had full access to the original data and vouch for the completeness and veracity of the data and data analyses. All authors contributed to data interpretation and to the writing of the report, made final decisions on all parts of the report, and approved the final version of the submitted report. PHB, TO and VS designed the study. PHB interviewed and enrolled the patients. TAH measured NT-proBNP and hs-cTnT. AHD and VS confirmed the diagnoses, undertook the statistical analyses and generated tables and figures. VS reviewed the radiographs. AHD and PHB analyzed the ECGs.

\section{Acknowledgements}

We thank Dr. Anke Neukamm, Division of Internal Medicine, Akershus University Hospital, and Dr. Lars Øivind Høiseth, Dept. of Anesthesiology, Oslo University Hospital and University of Oslo, for scoring the electrocardiograms, and Dr. Bo Daniel Karlsson, Dept. of Radiology, Akershus University Hospital, for reviewing the radiographs.

\section{Funding}

The study was financed by The Norwegian Association of Heart and Lung Patients through funds from the Norwegian ExtraFundation for Health and Rehabilitation. They had no role in the study design, collection of data, writing of the manuscript or decision to submit for publication.

\section{Author details}

'Division of Medicine, Akershus University Hospital and Institute of Clinical Medicine, University of Oslo, Oslo, Norway. ${ }^{2}$ Unit of Medical Biochemistry,
Division of Diagnostics and Technology, Akershus University Hospital and University of Oslo, Oslo, Norway. ${ }^{3}$ Akershus University Hospital, 1478, Lørenskog, Norway.

Received: 17 August 2012 Accepted: 26 October 2012

Published: 29 October 2012

\section{References}

1. Patel AR, Hurst JR: Extrapulmonary comorbidities in chronic obstructive pulmonary disease: state of the art. Expert review of respiratory medicine 2011, 5(5):647-662.

2. Sidney S, Sorel M, Quesenberry CP Jr, DeLuise C, Lanes S, Eisner MD: COPD and incident cardiovascular disease hospitalizations and mortality: Kaiser permanente medical care program. Chest 2005, 128(4):2068-2075.

3. Huiart L, Ernst P, Suissa S: Cardiovascular morbidity and mortality in COPD. Chest 2005, 128(4):2640-2646.

4. Curkendall SM, DeLuise C, Jones JK, Lanes S, Stang MR, Goehring E Jr, She D: Cardiovascular disease in patients with chronic obstructive pulmonary disease, Saskatchewan Canada cardiovascular disease in COPD patients. Ann Epidemiol 2006, 16(1):63-70.

5. Sin DD, Anthonisen NR, Soriano JB, Agusti AG: Mortality in COPD: role of comorbidities. Eur Respir J 2006, 28(6):1245-1257.

6. Feary JR, Rodrigues LC, Smith CJ, Hubbard RB, Gibson JE: Prevalence of major comorbidities in subjects with COPD and incidence of myocardial infarction and stroke: a comprehensive analysis using data from primary care. Thorax 2010, 65:956-962.

7. Brekke PH, Omland T, Smith P, Soyseth V: Underdiagnosis of myocardial infarction in C. Respir Med 2008, 102(9):1243-1247.

8. Buajordet I, Ebbesen J, Erikssen J, Brors O, Hilberg T: Fatal adverse drug events: the paradox of drug treatment. J Intern Med 2001, 250(4):327-341.

9. McCullough PA, Hollander JE, Nowak RM, Storrow AB, Duc P, Omland T, McCord J, Herrmann HC, Steg PG, Westheim A, et al: Uncovering heart failure in patients with a history of pulmonary disease: rationale for the early use of B-type natriuretic peptide in the emergency department. Acad Emerg Med 2003, 10(3):198-204.

10. Rutten FH, Moons KG, Cramer MJ, Grobbee DE, Zuithoff NP, Lammers JW, Hoes AW: Recognising heart failure in elderly patients with stable chronic obstructive pulmonary disease in primary care: cross sectional diagnostic study. BMJ 2005, 331(7529):1379.

11. Brekke PH, Omland T, Holmedal SH, Smith P, Soyseth V: Determinants of cardiac troponin T elevation in COPD exacerbation - a cross-sectional study. BMC Pulm Med 2009, 9:35.

12. McAllister DA, Maclay JD, Mills NL, Leitch A, Reid P, Carruthers R, O'Connor J, McAlpine L, Chalmers G, Newby DE, et al: Diagnosis of myocardial infarction following hospitalisation for exacerbation of COPD. Eur RespirJ 2012, 39(5):1097-1103.

13. Hoiseth AD, Omland T, Hagve TA, Brekke PH, Soyseth V: Determinants of high-sensitivity cardiac troponin T during acute exacerbation of chronic obstructive pulmonary disease: a prospective cohort study. BMC pulmonary medicine 2012, 12(1):22.

14. Hoiseth AD, Neukamm A, Karlsson BD, Omland T, Brekke PH, Soyseth V: Elevated high-sensitivity cardiac troponin $T$ is associated with increased mortality after acute exacerbation of chronic obstructive pulmonary disease. Thorax 2011, 66(9):775-781.

15. Chang CL, Robinson SC, Mills GD, Sullivan GD, Karalus NC, McLachlan JD, Hancox RJ: Biochemical markers of cardiac dysfunction predict mortality in acute exacerbations of COPD. Thorax 2011.

16. Dickstein K, Cohen-Solal A, Filippatos G, McMurray JJ, Ponikowski P, Poole-Wilson PA, Stromberg A, van Veldhuisen DJ, Atar D, Hoes AW, et al: ESC Guidelines for the diagnosis and treatment of acute and chronic heart failure 2008: the Task Force for the Diagnosis and Treatment of Acute and Chronic Heart Failure 2008 of the European Society of Cardiology. Developed in collaboration with the Heart Failure Association of the ESC (HFA) and endorsed by the European Society of Intensive Care Medicine (ESICM). Eur Heart J 2008, 29(19):2388-2442.

17. Medina AM, Marteles MS, Saiz EB, Martinez SS, Laiglesia FR, Rodriguez JA, Perez-Calvo Jl: Prognostic utility of NT-proBNP in acute exacerbations of chronic pulmonary diseases. Eur J Intern Med 2011, 22(2):167-171.

18. Stolz D, Breidthardt T, Christ-Crain M, Bingisser R, Miedinger D, Leuppi J, Mueller B, Tamm M, Mueller C: Use of B-type natriuretic peptide in the 
risk stratification of acute exacerbations of COPD. Chest 2008, 133(5):1088-1094.

19. Leuchte $H H$, Baumgartner RA, Nounou ME, Vogeser M, Neurohr C, Trautnitz $\mathrm{M}$, Behr J: Brain natriuretic peptide is a prognostic parameter in chronic lung disease. Am J Respir Crit Care Med 2006, 173(7):744-750.

20. van Gestel YR, Goei D, Hoeks SE, Sin DD, Flu WJ, Stam H, Mertens FW, Bax JJ, van Domburg RT, Poldermans D: Predictive value of NT-proBNP in vascular surgery patients with COPD and normal left ventricular systolic function. Copd 2010, 7(1):70-75.

21. Gale CP, White JE, Hunter A, Owen J, Allen J, Watson J, Holbrook I, Durham NP, Pye MP: Predicting mortality and hospital admission in patients with COPD: significance of NT pro-BNP, clinical and echocardiographic assessment. J Cardiovasc Med (Hagerstown) 2011, 12(9):613-618

22. Stamm JA, Belloli EA, Zhang Y, Bon J, Sciurba FC, Gladwin MT: Elevated $\mathrm{N}$-terminal pro-brain natriuretic peptide is associated with mortality in tobacco smokers independent of airflow obstruction. PLOS One 2011, 6(11):e27416.

23. Inoue $Y$, Kawayama $T$, Iwanaga $T$, Aizawa H: High plasma brain natriuretic peptide levels in stable COPD without pulmonary hypertension or cor pulmonale. Intern Med 2009, 48(7):503-512.

24. Gemici G, Erdim R, Celiker A, Tokay S, Ones T, Inanir S, Oktay A: B-type natriuretic peptide levels in patients with COPD and normal right ventricular function. Adv Ther 2008, 25(7):674-680.

25. Martins CS, Rodrigues MJ, Miranda VP, Nunes JP: Prognostic value of cardiac troponin I in patients with COPD acute exacerbation. Neth J Med 2009, 67(10):341-349.

26. Rautaharju PM, Warren JW, Jain U, Wolf HK, Nielsen CL: Cardiac infarction injury score: an electrocardiographic coding scheme for ischemic heart disease. Circulation 1981, 64(2):249-256.

27. Hurst JR, Vestbo J, Anzueto A, Locantore N, Mullerova H, Tal-Singer R, Miller B, Lomas DA, Agusti A, Macnee W, et al: Susceptibility to exacerbation in chronic obstructive pulmonary disease. N Engl J Med 2010, 363(12):1128-1138

28. Mantel N: Evaluation of survival data and two new rank order statistics arising in its consideration. Cancer chemotherapy reports Part 1 1966, 50(3):163-170.

29. Kleinbaum DG, Klein M: Survival Analysis. A Self-Learning Text. New York: Springer; 2005

30. Abroug F, Ouanes-Besbes L, Nciri N, Sellami N, Addad F, Hamda KB, Amor AB, Najjar MF, Knani J: Association of left-heart dysfunction with severe exacerbation of chronic obstructive pulmonary disease: diagnostic performance of cardiac biomarkers. Am J Respir Crit Care Med 2006, 174(9):990-996.

31. Omland T, Hagve TA: Natriuretic peptides: physiologic and analytic considerations. Heart Fail Clin 2009, 5(4):471-487.

32. Hall C: NT-ProBNP: the mechanism behind the marker. J Card Fail 2005, 11(5 Suppl):S81-83.

33. Arjamaa $\mathrm{O}$, Nikinmaa M: Hypoxia regulates the natriuretic peptide system. Int J Physiol Pathophysiol Pharmacol 2011, 3(3):191-201.

34. Renzetti AD Jr, McClement JH, Litt BD: The Veterans Administration cooperative study of pulmonary function. 3. Mortality in relation to respiratory function in chronic obstructive pulmonary disease. Am J Med 1966, 41(1):115-129.

35. Mascarenhas J, Azevedo A, Bettencourt P: Coexisting chronic obstructive pulmonary disease and heart failure: implications for treatment, course and mortality. Curr Opin Pulm Med 2010, 16(2):106-111.

36. Gariani K, Delabays A, Perneger TV, Agoritsas T: Use of brain natriuretic peptide to detect previously unknown left ventricular dysfunction in patients with acute exacerbation of chronic obstructive pulmonary disease. Swiss medical weekly 2011, 141:w13298.

37. Baggish AL, Siebert U, Lainchbury JG, Cameron R, Anwaruddin S, Chen A, Krauser DG, Tung R, Brown DF, Richards AM, et al: A validated clinical and biochemical score for the diagnosis of acute heart failure: the ProBNP Investigation of Dyspnea in the Emergency Department (PRIDE) Acute Heart Failure Score. Am Hear J 2006, 151(1):48-54.

38. Ouanes I, Jalloul F, Ayed S, Dachraoui F, Ouanes-Besbes L, Fekih Hassen M, Elatrous S, Abroug F: N-terminal proB-type natriuretic peptide levels aid the diagnosis of left ventricular dysfunction in patients with severe acute exacerbations of chronic obstructive pulmonary disease and renal dysfunction. Respirology 2012, 17(4):660-666.
39. White HD: Pathobiology of troponin elevations: do elevations occur with myocardial ischemia as well as necrosis? J Am Coll Cardiol 2011, 57(24):2406-2408.

40. Latini R, Masson S, Anand IS, Missov E, Carlson M, Vago T, Angelici L, Barlera S, Parrinello G, Maggioni AP, et al: Prognostic value of very low plasma concentrations of troponin $\mathrm{T}$ in patients with stable chronic heart failure. Circulation 2007, 116(11):1242-1249.

41. Omland T, de Lemos JA, Sabatine MS, Christophi CA, Rice MM, Jablonski KA, Tjora S, Domanski MJ, Gersh BJ, Rouleau JL, et al: A sensitive cardiac troponin T assay in stable coronary artery disease. N Engl J Med 2009, 361(26):2538-2547.

42. de Lemos JA, Drazner MH, Omland T, Ayers CR, Khera A, Rohatgi A, Hashim I, Berry JD, Das SR, Morrow DA, et al: Association of troponin T detected with a highly sensitive assay and cardiac structure and mortality risk in the general population. JAMA: the journal of the American Medical Association 2010, 304(22):2503-2512.

43. deFilippi CR, de Lemos JA, Christenson RH, Gottdiener JS, Kop WJ, Zhan M, Seliger SL: Association of serial measures of cardiac troponin T using a sensitive assay with incident heart failure and cardiovascular mortality in older adults. JAMA: the journal of the American Medical Association 2010, 304(22):2494-2502

44. Seemungal TA, Hurst JR, Wedzicha JA: Exacerbation rate, health status and mortality in COPD-a review of potential interventions. Int J Chron Obstruct Pulmon Dis 2009, 4:203-223.

45. Hosmer DW, Lemeshow S, May S: Applied survival analysis: regression modeling of time-to-event data. 2nd edition. Hoboken, N.J.: WileyInterscience; 2008.

46. Brekke PH, Omland T, Holmedal SH, Smith P, Soyseth V: Troponin T elevation and long-term mortality after chronic obstructive pulmonary disease exacerbation. Eur Res pir J 2008, 31(3):563-570.

47. Fruchter O, Yigla M: Cardiac Troponin-I predicts long-term mortality in chronic obstructive pulmonary disease. COPD: Journal of Chronic Obstructive Pulmonary Disease 2009, 6(3):155-161.

doi:10.1186/1465-9921-13-97

Cite this article as: Høiseth et al:: NT-proBNP independently predicts long term mortality after acute exacerbation of COPD - a prospective cohort study. Respiratory Research 2012 13:97.

\section{Submit your next manuscript to BioMed Central and take full advantage of:}

- Convenient online submission

- Thorough peer review

- No space constraints or color figure charges

- Immediate publication on acceptance

- Inclusion in PubMed, CAS, Scopus and Google Scholar

- Research which is freely available for redistribution 